\title{
Reflexión histórica sobre el IVA en Colombia y sus implicaciones en la jurisprudencia nacional ${ }^{1}$
}

\section{Historical reflection on VAT in Colombia and its implications for national jurisprudence}

\author{
DOI: https://doi.org/10.17981/juridcuc.15.1.2019.06
}

Artículo de reflexión. Fecha de Recepción: 18/11/2018 Fecha de Aceptación: 16/07/2019

\author{
Eder Berdejo Giovanetti \\ Universidad Libre, Barranquilla (Colombia) \\ ederberdejoliz@gmail.com \\ Milagros Villasmil Molero \\ Universidad Libre, Barranquilla (Colombia) \\ milagrosd.villasmilm@unilibre.edu.co
}

Para citar este artículo:

Berdejo, E.. y Villasmil, M. (2019). Reflexión histórica sobre el IVA en Colombia y sus implicaciones en la jurisprudencia nacional. JURÍDICAS CUC, 15(1). 163-186. DOI: http://dx.doi.org/10.17981/ juridcuc.15.1.2019.06

\section{Resumen}

El artículo hace una reflexión histórica sobre el Impuesto sobre el Valor Agregado (IVA) en el contexto colombiano y sus implicaciones en la jurisprudencia nacional, haciendo énfasis en la relevancia de dicho tributo desde una perspectiva legal, social y económica. El objetivo de la investigación es analizar la incidencia de las modificaciones que ha sufrido el IVA con el fin de conocer sus implicaciones actuales desde la perspectiva jurídica y económica. Por tanto, a través de un análisis hermenéutico de fuentes doctrinales, legislativas y jurisprudenciales, se abordaron las transformaciones por las cuales ha pasado el IVA con los cambios de gobierno y las necesidades económicas del contexto. Tal análisis permite comprender como este impuesto es un tópico que requiere especial protección, pues la dilapidación de este la conlleva a la desigualdad social, la pobreza y en consecuencia sucumbe en el modelo de subdesarrollo, y por ende, estanca el progreso socio-económico del contexto colombiano.

Palabras clave: Reflexión histórica; Impuesto sobre el Valor Agregado (IVA); jurisprudencia; tributo.
Abstract

The article makes a historical reflection on Value Added Tax (IVA) in the Colombian context and its implications in national jurisprudence, emphasizing the relevance of such tax from a legal, social and economic perspective. The objective of the research is to analyze the incidence of the modifications that IVA has suffered in order to know its current implications from a legal and economic perspective. Therefore, through a hermeneutic analysis of doctrinal, legislative and jurisprudential sources, the transformations through which IVA has gone through with changes of government and the economic needs of the context were addressed. Such analysis allows us to understand how this tax is a topic that requires special protection, since the squandering of this tax leads to social inequality, poverty and consequently succumbs to the underdevelopment model, and therefore, stagnates the socio-economic progress of the Colombian context.

Keywords: Historical reflection; Value Added Tax (IVA); jurisprudence; tax. 


\section{INTRODUCCIÓN}

El Impuesto sobre el Valor Agregado (IVA), es el tributo que están obligados a desembolsar todos los ciudadanos, debido a que el mismo está intrínseco en la mayoría de las actividades de consumo, bienes y servicios. Ahora bien, una de las definiciones puntuales con respecto al IVA, proviene del estudio de Hoyos (2014), considerándolo como un impuesto relevante desde distintas ópticas, siendo la primera el "constituir una singular fuente de recaudos para los Estados" (p. 2), segundo, "evita y controla la evasión" (p. 2), tercero, "canaliza información importante para el Estado sobre las actividades económicas, y la situación de los contribuyentes" (p. 2), y finalmente, "si obedece a estándares internacionales, debe servir por igual al recaudo y el mantenimiento de las condiciones de competencia entre productos y servicios" (p. 2). También, para Villasmil y Polo (2018), el impuesto a las ventas o Impuesto al Valor Agregado comúnmente denominado IVA, es un tributo que tiene su efecto en el consumo de servicios, bienes y explotación de juegos de azar y suerte.

Entre tanto, es preciso aseverar, como dicho impuesto, es considerado una carga fiscal sobre el consumo y se encuentra amparado constitucionalmente en la legislación; ha sufrido modificaciones al transcurrir el tiempo, adaptándose además a las necesidades económicas de un determinado contexto socioeconómico, conllevando estas modificaciones a "nuevas formas de organización administrativa, de innovaciones en los estilos de intervención y gestión en el Estado" (Ramírez, 2012, p. 83), develando distintas formas de recaudación de impuestos.

En lo que respecta al Impuesto sobre el Valor Agregado colombiano (IVA), es una de las principales fuentes de ingresos tributarios del país, y a la vez el de mayor importancia en el marco de la economía nacional, por lo anterior, a lo largo del tiempo, el impuesto en mención ha sufrido modificaciones legislativas 
que han sido la raíz seminal para el surgimiento de varias reformas tributarias, siendo la más reciente la que se encuentra consagrada en la Ley 1819 (2016).

Por lo demás, resulta de suma importancia realizar un estudio hermenéutico-analítico, con el fin de comprender aspectos fundamentales sobre la metamorfosis legislativa que se ha dado al transcurrir de los años en lo que respecta al Impuesto sobre el Valor Agregado (IVA), conllevando entonces a establecer como fundamental el analizar la incidencia de las modificaciones que ha sufrido el IVA con el fin de conocer sus implicaciones actuales desde la perspectiva jurídica y económica.

Para conseguir el logro propuesto, el modus operandi que se sigue, esta basado en el seguimiento de las siguientes metas específicas: identificar las diferentes doctrinas por las cuales se origina este impuesto, también, plasmar las normas colombianas con las cuales a través del tiempo se han legislado sobre esta carga, y además, conocer los conceptos jurisprudenciales versados sobre esta materia.

Teniendo en cuenta lo anterior, se establece un cuestionamiento puntual, el cual fue determinante para responder con certeza a los intereses planteados:

¿Cuál ha sido la incidencia de las transformaciones legislativas sufridas por el Impuesto sobre el Valor Agregado (IVA), a nivel económico, social y legislativo?

\section{Metodología}

En lo que respecta a la metodología utilizada, se hace énfasis en el seguimiento de las pautas de un estudio descriptivo documental, con enfoque cualitativo, además de un diseño bibliográfico y analítico, consistente en el análisis hermenéutico de fuentes doctrinales, legislativas y jurisprudenciales aplicables al caso en cuestión. 
$\mathrm{Al}$ poner en marcha la consulta en bases de datos jurisprudenciales, y de las diferentes cortes en asuntos referentes al presente análisis y de igual manera las normas tributarias, conceptos del máximo órgano recaudador de impuestos que para este caso corresponde a la Dirección de Impuestos y Aduanas Nacionales (DIAN), como también a la Constitución Política y a la Corte Constitucional colombiana, así mismo, artículos investigativos y libros que facilitaron la recopilación de información, para finalmente dar un enfoque hacia un método analítico sintético del tema propuesto, para proporcionar un estudio más amplio del tema hacia posteriores estudios del Impuesto sobre el valor Agregado (IVA).

\section{Desarrollo}

\section{Linea de Tiempo del Impuesto sobre Valor Agregado (IVA)}

El surgimiento del Impuesto sobre el Valor Agregado, hasta donde se tiene conocimiento, se remonta al Imperio Romano, conocido con el nombre en latín de Centesima rerum venalium (centésimo del valor de todo vendido), el cual, de acuerdo con Soler (2012), era destinado a "la financiación de las guerras del imperio, en aras de la conquista de más tierras" (p. 6). El impuesto en cuestión, consistía en abonar una centésima por cuenta de edificios, terrenos y animales, entre otros (Soler, 2012).

Entre tanto, de acuerdo con otros estudios, los vestigios primigenios que se tienen sobre los impuestos en los productos, provienen de la Antigua Grecia, donde, por ejemplo en Atenas, en cuanto a la imposición indirecta de los impuestos, los ricos debían "donar" obligatoriamente para el recaudo de fondos en la promoción de la guerra y obras públicas (Finley, 1999).

Ahora bien, en cuanto a los impuestos directos, base fundamental de la economía de la mayoría de ciudades estado griegas, se imponían impuestos sobre las casas, los esclavos, el ganado, 
el vino, el heno, entre otros, los cuales eran recolectados por los telônai (publicanos) (Finley, 1999).

Empero, al socavar exhaustivamente en la historia, ya desde los egipcios, se recaudaban impuestos en nombre del faraón a campesinos, artesanos y granjeros, en base a la comercialización de sus productos, recurriendo a maneras poco ortodoxas para la obtención de la dádiva por parte de los agentes fiscales, quienes llevaban los registros de los pagos en papiros, en los cuales quedaban registrados de por vida (Finley, 1999).

Ahora bien, en Colombia, el Impuesto sobre el Valor Agregado, surgió en el gobierno del presidente Guillermo León Valencia en el año de 1963, quien mediante Decreto 3288 (1963), estableció a través del Ministerio Público legalmente la obligación del tributo, a los productos y servicios del sector de la manufactura y exportación, exceptuando los artículos alimenticios de consumo popular, los útiles escolares y los fármacos. Las características de este decreto destacaban, según Jaramillo y Tovar (2008):

(...) las tarifas en el marco de este decreto quedaron gravadas al $10 \%, 8 \%$ y $3 \%$ para productos no enumerados, seguidamente el Decreto 3288 de 1963, Artículo 7. La gasolina para este entonces tenía un tratamiento diferencial, que se pretendía regular en un decreto especial (p. 74).

En cuanto a su destinación, el Gobierno Nacional podía ceder a los Departamentos, mediante contratos a los municipios o al Distrito Especial de Bogotá, la administración y producido del impuesto sobre las ventas de alguno o algunos de los artículos a él sujetos, con el fin de que dichas entidades lo destinaran al sostenimiento de hospitales y demás establecimientos de asistencia pública y educación (Jaramillo y Tovar, 2008).

Dos años más adelante, el Decreto 377 (1965), hace una modificación importante al IVA, siendo "la sustitución del método de sustracción de costos por el de impuestos contra impuestos". (Ramírez, 2012, p. 85). Así, este tributo empezieza a moldearse 
en la estructura de valor agregado que hoy aparece en todas las facturas de compra como IVA, (Decreto 1595 (1966); Decreto 435 (1971); Decreto 1970 (1974) y Ley 20631 (1975)).

Al mandato del presidente Alfonso López Michelsen (19741978), se le atribuye la "unificación del Impuesto de Renta y sus complementarios", también, "se incluyen las empresas industriales y comerciales del estado como contribuyentes, además de que "se precisan los sujetos pasivos del impuesto sobre la rente", presentes en los Decretos 2053 (1974), 2247 (1974), 2821 (1974). Entre tanto, a pesar de los esfuerzos del gobierno por disminuir la crisis económica y el déficit fiscal, se somete el IVA a tributar en todas sus fases y es precisamente bajo estas características que se vuelve un impuesto plurifásico.

En base a lo anterior, Castañeda (2014) afirma que:

La reforma del presidente López, mejoró la efectividad del sistema. Los ingresos tributarios se incrementaron 36\% entre 1974 y 1975, e incluso, a pesar de la evasión y la elusión generalizada en renta, se consiguió que el recaudo creciera otro 17\% en 1977, fue así como bajo este gobierno se consiguieron algunos de los mejores resultados económicos del Siglo XX (2014, p. 187).

Por su parte, en el gobierno de Belisario Betancourt (19821986), se sigue ampliando el universo de contribuyentes, extendiendo a su vez el impuesto al comercio al detal, o, en otras palabras, al consumidor final. En dicho mandato se establecen el Decreto 3803 (1982), en el cual se "dictan normas para controlar la evasión tributaria y se hacen precisiones en materia de procedimiento" (p. 1). También, el Decreto 2160 (1986), con el fin de "armonizar las medidas tributarias con el control fiscal, contable y económico" (p. 1).

Con el Decreto 3541 (1983), se extendió "el impuesto comercial al detal, es decir, al consumidor final”. Por ello, Hoyos (2014) menciona lo siguiente a propósito de este decreto: 
(...) a mayores contribuyentes se hace una consolidación de tarifa al $10 \%$, pero incluye más servicios en la base y organiza una mejor administración del tributo, la simplificación del mecanismo de las declaraciones del impuesto y la consolidación de la información con la declaración del impuesto sobre la renta (p. 15).

Aparte, con este decreto nace el régimen simplificado aplicable para pequeños comerciantes, en la parte contable, y con el fin de permitir la tramitología en caso de devoluciones a saldos a favor, se establece la obligatoriedad de llevar cuenta mayor y de balance denominada impuesto a las ventas por pagar (Cubero y Luque, 2006). Por su parte, el Decreto 624 (1989, artículos 469 y 470) introdujo "tarifas del $10 \%$ para unos servicios y del $20 \%$ para telefonía, unos bienes sometidos a tarifa diferencial del $35 \%$ y $20 \%$ y unas tarifas especiales para los derivados del petróleo y por otro lado la cerveza del 8\%” (1989, p. 9).

Ahora, la Ley 75 (1986), establece la regulación "del contenido de impuesto de renta y el trámite para devolución de saldo en impuesto de IVA”. Por su parte, la Ley 49 (1990), contemplaba "la tarifa general del $12 \%$, pasando unos bienes a la calidad de excluidos del impuesto, así mismo se mantienen las tarifas diferenciales"; y años después se promulga la Ley 6 (1992), estableciendo "tarifas del $12 \%$ y a partir del año siguiente a $14 \%$ hasta 1997". Sin embargo, la Ley 223 (1995), artículo 14 establece "la modificación al artículo 468 del Estatuto Tributario nacional quedaría el impuesto de IVA en su tarifa general al 16\%, para los años de 1996, 1997, 1998 y en adelante" (Jaramillo y Tovar, 2010).

En continuidad con el lineamiento histórico, en la Ley 383 (1997), en su artículo 22, se estableció "responsabilidad penal al agente retenedor o responsable del impuesto que omita consignar el pago de IVA” (p. 1); seguidamente la Ley 488 (1998), redujo "los bienes excluidos que no causan impuesto, además baja la tarifa general a $15 \%$ en el mes de noviembre de 1988, 
la adquisición de bienes de capital al momento de presentar el impuesto de renta quedo eliminado" (p. 1). Por su parte, la Ley 633 (2000), "aumenta la tarifa general al 16\%" (p. 1). También, la Ley 788 (2002), agrega "una tarifa de 7\%, 10\% y 20\%, disminuyeron los bienes excluidos y otros bienes pasan de exentos a excluidos" (p. 1), siendo en el Decreto 2502 (2005), donde "la retención de IVA baja del $75 \%$ al 50\%” (p. 1).

Así, el Decreto 127 (2010), en su artículo 3, modifica el artículo 420 del Estatuto Tributario Nacional en su inciso 4, estableciendo "a partir del 1 de febrero de 2010, en los juegos de suerte y azar se aplicará la tarifa general prevista en este estatuto, es decir el 16\%" (p. 1). Entre tanto, la Ley 1430 de (2010), realiza una modificación al artículo 476 del Estatuto Tributario Nacional, excluyendo de IVA en el servicio de conexión y acceso a internet de los estratos socioeconómicos 1, 2 y 3.

De otro lado, el Decreto 2623 (2014), en su artículo 25 y siguientes, "separa a los responsables del pago del impuesto de forma bimestral, cuatrimestral y anual". Por su parte, la Ley 1819 de (2016), "incrementa la tarifa general de IVA al 19\%", y establece la modificación del artículo 468 así:

A partir del año gravable 2017, del recaudo del impuesto sobre las ventas un (1) punto se destinará así: a) 0.5 puntos se destinarán a la financiación del aseguramiento en el marco del Sistema General de Seguridad Social en Salud; b) 0.5 puntos se destinarán a la financiación de la educación. El cuarenta por ciento (40\%) de este recaudo se destinará a la financiación de la Educación Superior Pública otros de los cambios concurren en que las personas jurídicas responsables del pago del tributo, aunque vendan a crédito tienen la obligación de realizar el pago del impuesto a más tardar dentro de los dos meses siguientes al vencimiento del plazo de la declaración so pena de la apertura de la responsabilidad penal. Además, una tarifa diferencial del $5 \%$ y unos bienes exentos gravados al $0 \%$ (p. 1). 
TABla 1.

Linea de tiempo: trascendencia del IVA en Colombia

\begin{tabular}{|c|c|}
\hline Fundamento Legal & Descripción \\
\hline Decreto 3288 (1963) & $\begin{array}{l}\text { Impuesto Monofásico: cobraba a una sola fase de la } \\
\text { producción y distribución. Era Indirecto y se aplicaba } \\
\text { con el Impuesto a las Ventas. }\end{array}$ \\
\hline Decreto 1595 (1966) & $\begin{array}{l}\text { Se aumenta los responsables de su pago determinando } \\
\text { más contribuyentes y hechos generadores. A partir } \\
\text { de este momento el IVA se convirtió en un impuesto } \\
\text { plurifásico, siendo solo de primera etapa. Incorporando } \\
\text { tarifas diferenciales de } 10 \% \text { y } 8 \% \text { que se elevaron al } \\
15 \% \text {, la tarifa general se mantuvo en el } 3 \% \text {. }\end{array}$ \\
\hline Decreto 435 (1971) & $\begin{array}{l}\text { Introduce en Colombia el Impuesto al Valor Agregado } \\
\text { a los servicios: } \\
\text { La causación se da al momento de la importación, las } \\
\text { tarifas para dicho rubro aumentaron entre el } 4 \%, 10 \% \text {, } \\
15 \% \text { y } 25 \% \text {, valores significativos con relación al } 3 \% \text {, } \\
8 \%, 10 \% \text {, y } 15 \% \text {, respectivamente. }\end{array}$ \\
\hline $\begin{array}{l}\text { Decreto de } \\
\text { Emergencia } \\
\text { Económica } 1970 \\
\text { (1974) }\end{array}$ & $\begin{array}{l}\text { Decreto de emergencia económica y realiza una reforma } \\
\text { estructural al impuesto sobre las ventas. A pesar de } \\
\text { mantener el impuesto como un tributo plurifásico de } \\
\text { primera etapa, se aumenta el universo de aportantes, } \\
\text { agregando nuevos hechos generadores y ampliando } \\
\text { las bases para su aplicación. La tarifa general para } \\
\text { bienes gravados queda en } 15 \% \text {, y para otros servicios } \\
\text { se establece en } 4 \%, 6 \%, 10 \%, 15 \% \text { y } 35 \% \text {. }\end{array}$ \\
\hline $\begin{array}{l}\text { Decreto de Ley } 3541 \\
\text { (1983) }\end{array}$ & $\begin{array}{l}\text { Con este decreto se sigue ampliando el universo de } \\
\text { contribuyentes, extendiendo a su vez el impuesto al } \\
\text { comercio al detal, o, en otras palabras, al consumidor } \\
\text { final. Con este decreto nace el régimen simplificado } \\
\text { que aplica para los pequeños comerciantes, en la parte } \\
\text { contable, y con el fin de permitir la tramitología en caso } \\
\text { de las devoluciones de los saldos a favor, se establece la } \\
\text { obligatoriedad de llevar la cuenta mayor y de balance } \\
\text { denominada "impuesto a las ventas por pagar". }\end{array}$ \\
\hline $\begin{array}{l}\text { Decreto de Ley } 624 \\
\text { (1986) }\end{array}$ & $\begin{array}{l}\text { Es la culminación de un trabajo arduo que da origen } \\
\text { al primer Estatuto Tributario de numeración continua, } \\
\text { consolidando y armonizando toda la legislación que } \\
\text { regula los impuestos administrados por la DIAN. } \\
\text { Este estatuto también es utilizado como base para los } \\
\text { estatutos departamentales y distritales. }\end{array}$ \\
\hline
\end{tabular}




\begin{tabular}{ll}
\hline & Para este año entra en vigencia la Ley 75 , la cual \\
& viene a regular cuál debe ser el contenido de las \\
& declaraciones: regula la aproximación de las cifras al \\
Ley 75 (1986) & múltiplo mil más cercano y reglamenta los términos \\
& para que el contribuyente tramite las devoluciones de \\
& saldos a favor para el IVA.
\end{tabular}

La Ley 49 de 1990 unificó la tarifa del IVA en 12\%, aunque se mantuvieron tarifas diferenciales de $4 \%, 3 \%$, $8 \%, 15 \%, 20 \%$ y $35 \%$, y se incorporaron como excluidos algunos bienes que con anterioridad se encontraban como exentos. Este cambio se da con la disminución de

Ley 49 (1990) tarifas arancelarias. Lo más representativo en dicho cambio es que la cuenta del Estado, al verse afectada en su presupuesto, se trató de ajustar con un aumento de 2 puntos porcentuales en la tarifa general y una disminución del universo de los productos excluidos, lo que significó mayor recaudo para cubrir el gasto del Estado.

A partir de aquí se estableció un gravamen general sobre los servicios, quedando sin impuesto únicamente los productos de la canasta familiar. Para incentivar

Ley 6 (1992) la producción, se decretaron exclusiones a productores de la canasta familiar en la compra de maquinaria no producida en el país. Finalmente, la reforma determinó a partir de 1993 la tarifa sería del 14\%.

Nuevamente los faltantes de caja se tratan de cubrir con la ley 223 de 1995, que viene a Aumentar la tarifa del $14 \%$ a $16 \%$, con la introducción de cambios en la base gravable. Como un anticipo al faltante de caja,

Ley $223(1995)$ se establece un mecanismo de retención en la fuente del impuesto sobre las ventas, decretando que el 50\% del valor del impuesto fuera descontado a momento del pago al generador del mismo a título de retención. Dicho valor podría ser aplicado por el contribuyente en su declaración de IVA.

Ley 383 (1997)

La Ley 383 de 1997 determinó la aplicación de sanciones penales para quienes no consignaran el IVA recaudado a favor del Estado.

Ley 1819 (2016)

La Tarifa subió del 16\% al 19\% actualmente vigente al 2018.

Fuente: Adaptado de Castañeda (2014). 


\section{El IVA en la Jurisprudencia Nacional}

La jurisprudencia nacional a través de la Corte Constitucional colombiana en la Sentencia C-583 (1996), preceptúa el hecho generador, "como la situación susceptible de generar la obligación tributaria" (p. 1). Es un impuesto sobre el consumo que se realiza de manera indirecta, así lo preceptúa la jurisprudencia nacional colombiana, y la misma corporación señala el sujeto activo en la Sentencia C-987 (1999), describiendo varios sujetos de acuerdo a las problemáticas debido a la hermenéutica. Entre ellos tenemos estos tres conceptos:

(...) el primero correspondiente al sujeto activo de la potestad tributaria; quien tiene la facultad de crear el impuesto, el sujeto activo de la potestad tributaria, segundo, el acreedor de la suma pecuniaria y, tercero, el beneficiario del tributo; la entidad que dispone del tributo (1999, p. 12).

Otro de los elementos de tributo es el sujeto pasivo del impuesto, del cual ha descrito la Corte Constitucional dos clases de éste: el primero de $I U R E$, a quien formalmente le corresponde el pago del impuesto y el segundo, el de FACTO, quien en ultimas soporta las consecuencias económicas del gravamen. Ahora bien, la doctrina tributaria ha descrito dos clases de sujeto pasivo, siendo éstos, el sujeto pasivo económico, que no es otro que el consumidor final, quien si bien no es parte de la obligación tributaria sustancial, desde el punto de vista económico es la persona en ultimas que lo asume, siendo el segundo, el sujeto pasivo jurídico o de derecho, quien es el responsable del recaudo y las obligaciones que impone el Estado (declaración y pago del impuesto so pena de sanción administrativa y penal).

Además de los anteriores, uno de elementos fundamentales del Impuesto sobre el Valor Agregado es la base gravable, descrita por la Jurisprudencia Nacional como la magnitud o medición del hecho que se grava. Por último, otro de los aspectos 
relevantes es la tarifa, la cual "hace referencia al valor que se aplica a la base gravable cuyo valor determina el monto a pagar del impuesto".

Por su parte, a través de la Sentencia C-426 de (2005), el Impuesto al Valor Agregado (IVA), no incide de forma directa sobre el ingreso, sino sobre el costo de la producción y la venta, se obtienen del precio que paga el sujeto pasivo por la adquisición de un producto, en cuanto a sobre quien recae la carga del pago del tributo.

En continuidad con lo anterior, dice la Jurisprudencia de la Corte Constitucional colombiana en la Sentencia C-209 (2016), que existen dos clases de sujeto pasivo el obligado de IURE, es decir, quien en principio paga formalmente el impuesto, y de $F A C T O$, quien en últimas soporta las consecuencias económicas del gravamen.

Finalmente, el Impuesto al Valor Agregado hace parte de las tributaciones nacionales, gozan de especial protección constitucional y contribuye a alcanzar los fines sociales del estado, así lo consagran el artículo 334 (CP, 1991); artículo 362 (CP, 1991); artículo 365 (CP, 1991); artículo 366 (CP, 1991); artículo 367 (CP, 1991) y artículo 368 (CP, 1991) de la Constitución Política colombiana (CP). Entre tanto, el artículo 420 (ET, 2018), del Estatuto Tributario colombiano (ET), "regula los hechos sobre los que recae el impuesto de IVA". Teniendo en cuenta lo precisado a través de este apartado, fue pertinente hacer énfasis en el abordaje del Impuesto al Valor Agregado (IVA) en la doctrina del Federalismo Fiscal.

\section{El Impuesto al Valor Agregado (IVA) en la doctrina del Federalismo Fiscal}

El federalismo fiscal es entendido como aquellas funciones fiscales de los gobiernos, tanto del nivel central como el local, estando anclado dicho concepto a las necesidades de quienes administran, es decir, las específicas, siendo entonces de interés el sujeto 
al mando en cada sector, el cual debe conocer de forma directa acerca de las necesidades y puntos a fortalecer en su entorno, ya que, la extensa territorialidad dejaría por fuera algunos lugares fuera del alcance para cubrir de manera inmediata.

La aplicación del concepto de Federalismo Fiscal en el país, no resultó tarea de un solo momento, puesto que tuvo varios pasos que permitieron de cierta manera llegar a él, debido al tamaño de los gobiernos locales, los recursos propios, la transferencia del gobierno central y el endeudamiento público, representando este último una problemática que trunca el desarrollo económico en Colombia. Es así como en los años 80, se pasó a elegir alcaldes y gobernadores, precisamente para poner en marcha la teoría del Federalismo Fiscal, que permitiera una mejor organización de las necesidades del país; sin embargo, las administraciones locales no tenían independencia de los recursos, al ser estos manejados desde el gobierno central.

Sólo hasta el año de 1992 el gobierno de César Gaviria (19901994), se promulga la Ley 60 (1993), la cual dicta la distribución de competencias de conformidad con los artículos 151 y 288 de la Constitución Política y se distribuyen recursos según los artículos 356 y 357 que establecen las pautas para la asignación de recursos de los entes territoriales en materia de servicio de salud y educación.

\section{Conclusiones}

Este artículo tuvo como propósito el análisis histórico de la evolución de Impuesto al Valor Agregado (IVA), comenzando desde la primera vez que se avizoró desde los egipcios, pasando por los griegos y los romanos, para luego ser abordado de manera exhaustiva a partir de sus implicaciones en el contexto colombiano. Es preciso aseverar que, cuando muchos de los autores que han puntualizado en hacer una exégesis histórica sobre el impuesto en mención de manera general, refieren como vestigio 
primordial los aspectos de este impuesto en el Imperio Romano. Por lo anterior, la pertinencia de esta investigación radicó en el abordaje certero y meticuloso con respecto a la manera que ha avanzado dicho gravamen, diferenciándose de artículos investigativos como el de Cubero y Luque (2006) y Soler (2012).

Después de haber estudiado los antecedentes históricos del Impuesto al Valor Agregado en Colombia, se podrá responder con seguridad siguiente interrogante: ¿Es el IVA en Colombia un impuesto que goza de seguridad jurídica?, dicho cuestionamiento surge debido al panorama no tan claro, para el impuesto en materia de la pregunta, porque se supone que son los que contribuyen al pago de los impuestos, quienes con su aporte solventan las cargas del Estado para el desarrollo de éste.

Sin embargo, para poder el individuo establecer su proyecto de negocios lo primero que necesita es la seguridad legal de saber que toda la inversión en su negocio no se irá al pago de impuestos, una vez que éste confíe en la seriedad de la legislación y la protección que éste a través de sus Cortes le brinde, será apenas obvio que despliegue su plan de inversión con toda confianza.

Sin embargo, ¿podría pensarse o incluso afirmarse que es normal, seguro o confiable que en un Estado Social de Derecho se hayan legislado más de 20 veces en materia de IVA desde 1963?, es decir, en un promedio generalizado se ha hecho más o menos una modificación cada dos años y medio. El principio de seguridad jurídica debe ser unísono con el principio de confianza del contribuyente.

De otro lado, cabe analizar de manera detallada la distribución del recaudo por lo menos del impuesto estudiado, al ser éste uno de los más importantes en el sistema de política económica, si bien es afirmativo como la actual reforma tributaria consagrada a través de la Ley 1819 (2016), introdujo en una parte la manera cómo se distribuiría una parte del rubro del impuesto recaudado, desafortunadamente no hace descansar al contribu- 
yente el tema de la corrupción que se presenta al interior de los entes responsables de la distribución, como tampoco en las concesiones otorgadas para fines ser desarrollo social y económico, situación que conlleva a la evasión y elusión fiscal.

Los cambios políticos y económicos que el país ha tenido desde el año 2015 en adelante, han generado una gran incertidumbre tanto en lo social como en la parte fiscal. Los procesos del post-conflicto conllevan a reflexionar sobre el plan de reintegro social de los actores de la guerra interna, entre tanto, a pesar de que otros gobiernos han aportado dineros para tratar de manera asertiva la implicaciones del fin del conflicto armado, en el año 2016 surgió una reforma tributaria que, por ser tan controversial podría ser objeto de un posterior estudio, especialmente para la comprensión del por qué sube en tres puntos un impuesto, como también, qué condiciones se tienen en cuenta para los aumentos de los impuestos y cómo estos amenazan la seguridad jurídica.

Finalmente, el tema de la vigilancia y control de la distribución del impuesto es un tópico que requiere especial protección, pues es la dilapidación de estos lo que conlleva a la desigualdad social, la pobreza que en consecuencia sucumbe en el modelo de subdesarrollo y, por ende, estanca el progreso socio-económico del contexto colombiano.

\section{REFERENCIAS}

Castañeda, V. (2014). El gasto social como factor que favorece una mayor dependencia del IVA. Un análisis para el caso colombiano. Ecos de Economía, 18(38), 183215. Recuperado de http://www.redalyc.org/articulo. oa?id=329031558007

Cubero, A. y Luque, A. (2006). Los regímenes especiales del impuesto sobre sociedades y del IVA. Madrid: Tecnos. Recuperado de https://dialnet.unirioja.es/servlet/ libro?codigo $=652885$ 
Finley, M. (1999). The ancient economy. Los Angeles: University of California Press.

Hoyos, C. (2014). Aspectos críticos sobre del IVA en Colombia La reforma de 2012. Revista de Derecho Privado(51), 1-33. Recuperado de https://derechoprivado. uniandes.edu.co/components/com_revista/archivos/ derechoprivado/pri507.pdf

Jaramillo, C. y Tovar, J. (2010). Reflexiones sobre la teoría y la práctica del IVA en Colombia. Revista de Economía del Rosario, 10(2), 171-188.

Jaramillo, C. y Tovar, J. (2008). El impacto del Impuesto al Valor Agregado sobre el gasto en Colombia. Lecturas de Economía, 69-93. Recuperado de https://www. redalyc.org/pdf/1552/155215604003.pdf

Ramírez, M. (2012). Transformaciones del Estado en el gobierno local: La nueva gestión pública en Medellín. Reflexión Política, 14(28), 82-95. Recuperado de http:// www.redalyc.org/pdf/110/11025028007.pdf

República de Colombia. Asamblea Constituyente. (1991). Artículo 334. [Constitución Política de Colombia]. Gaceta Constitucional, 1(114). 23. Recuperado de http://babel.banrepcultural.org/cdm/compoundobject/ collection/p17054coll26/id/3850/show/3743/rec/8

República de Colombia. Asamblea Constituyente. (1991). Artículo 362. [Constitución Política de Colombia]. Gaceta Constitucional, 1(114). 25. Recuperado de http://www.constitucioncolombia.com/titulo-12/ capitulo-4/articulo-362

República de Colombia. Asamblea Constituyente. (1991). Artículo 365. [Constitución Política de Colombia]. Gaceta Constitucional, 1(114). 25. Recuperado de http://www.constitucioncolombia.com/titulo-12/ capitulo-5/articulo-365 
República de Colombia. Asamblea Constituyente. (1991). Artículo 366. [Constitución Política de Colombia]. Gaceta Constitucional, 1(114). 25. Recuperado de http://www.constitucioncolombia.com/titulo-12/ capitulo-5/articulo-366

República de Colombia. Asamblea Constituyente. (1991). Artículo 367. [Constitución Política de Colombia]. Gaceta Constitucional, 1(114). 25. Recuperado de http://www.constitucioncolombia.com/titulo-12/ capitulo-5/articulo-367

República de Colombia. Asamblea Constituyente. (1991). Artículo 368. [Constitución Política de Colombia]. Gaceta Constitucional, 1(114). 25. Recuperado de http://www.constitucioncolombia.com/titulo-12/ capitulo-5/articulo-368

República de Colombia. (2018). Artículo 420. [Estatuto Tributario Nacional]. Recuperado de https://estatuto. $\mathrm{co} / ? \mathrm{e}=718$

República de Colombia. Congreso de la República. (29 de diciembre de 2016). Por medio de la cual se adopta una reforma tributaria estructural, se fortalecen los mecanismos para la lucha contra la evasión y la elusión fiscal, y se dictan otras disposiciones. [Ley 1819]. DO: 50.101. Recuperado de http:// www.secretariasenado.gov.co/senado/basedoc/ ley_1819_2016.html

República de Colombia. Congreso de la República. (29 de diciembre de 2010). Por medio de la cual se dictan normas tributarias de control y para la competitividad. [Ley 1430]. DO: 47.937. Recuperado de http://www.secretariasenado.gov. co/senado/basedoc/ley_1430_2010.html 
República de Colombia. Congreso de la República. (diciembre de 27 de 2002). Por la cual se expiden normas en materia tributaria y penal del orden nacional y territorial; $y$ se dictan otras disposiciones. [Ley 788]. DO: 45.046. Recuperado de http://www.secretariasenado.gov.co/ senado/basedoc/ley_0788_2002.html

República de Colombia. Congreso de la República. (29 de diciembre de 2000). Por la cual se expiden normas en materia tributaria, se dictan disposiciones sobre el tratamiento a los fondos obligatorios para la vivienda de interés social y se introducen normas para fortalecer las finanzas de la Rama Judicial. [Ley 633]. DO: 44.275. Recuperado de https://www. funcionpublica.gov.co/eva/gestornormativo/norma. php? $\mathrm{i}=6285$

República de Colombia. Congreso de la República. (24 de diciembre de 1998). Por la cual se expiden normas en materia Tributaria y se dictan otras disposiciones fiscales de las Entidades Territoriales. [Ley 488]. DO: 43.460. Recuperado de https://www.funcionpublica. gov.co/eva/gestornormativo/norma.php? $\mathrm{i}=187$

República de Colombia. Congreso de la República. (10 de julio de 1997). Por la cual se expiden normas tendientes a fortalecer la lucha contra la evasión y el contrabando, y se dictan otras disposiciones. [Ley 383]. DO: 43.083. Recuperado de https://www.funcionpublica.gov.co/ eva/gestornormativo/norma.php?i=341

República de Colombia. Congreso de la República. (20 de diciembre de 1995). Por la cual se expiden normas sobre racionalización tributaria y se dictan otras disposiciones. [Ley 223]. DO: 42.160. Recuperado de http://www.secretariasenado.gov.co/senado/basedoc/ ley_0223_1995.html 
República de Colombia. Congreso de la República. (12 de agosto de 1993). Por la cual se dictan normas orgánicas sobre la distribución de competencias de conformidad con los artículos. [Ley 60]. DO: 40.987. Recuperado de https:// www.mineducacion.gov.co/1621/articles-85889_ archivo_pdf.pdf

República de Colombia. Congreso de la República. (30 de junio de 1992). Por la cual se expiden normas en materia tributaria, se otorgan facultades para emitir títulos de deuda pública interna, se dispone un ajuste de pensiones del sector público nacional y se dictan otras disposiciones. [Ley 6]. DO: 40.490. Recuperado de http:// www.secretariasenado.gov.co/senado/basedoc/ ley_0006_1992.html

República de Colombia. Congreso de la República. (28 de diciembre de 1990). Por la cual se reglamenta la repatriación de capitales, se estimula el mercado accionario, se expiden normas en materia tributaria, aduanera y se dictan otras disposiciones. [Ley 49]. DO: 39.615. Recuperado de https://www.alcaldiabogota. gov.co/sisjurMantenimiento/normas/Norma1. jsp?i=6545

República de Colombia. Congreso de la República. (13 de diciembre de 1986). Por la cual se expiden normas en materia tributaria, de catastro, de fortalecimiento y democratización del mercado de capitales, se conceden unas facultades extraordinarias y se dictan otras disposiciones. [Ley 75]. DO: 34.276. Recuperado de https:// www.funcionpublica.gov.co/eva/gestornormativo/ norma.php? $\mathrm{i}=74173$ 
República de Colombia. Presidencia de la República. (17 de diciembre de 2014). Por el cual se fijan los lugares y plazos para la presentación de las declaraciones tributarias y para el pago de los impuestos, anticipos y retenciones en la fuente $y$ se dictan otras disposiciones. [Decreto 2623]. DO: 49.368. Recuperado de https://www.funcionpublica.gov.co/ eva/gestornormativo/norma.php? $\mathrm{i}=60222$

República de Colombia. Presidencia de la República. (21 de enero de 2010). Por el cual se adoptan medidas en materia tributaria. [Decreto 127]. DO: 47.599. Recuperado de http://www.suin-juriscol.gov.co/ viewDocument.asp?id=1691438

República de Colombia. Presidencia de la República. (19 de julio de 2005). Por el cual se reglamenta parcialmente el artículo 437-1 del Estatuto Tributario. [Decreto 2502]. DO: 45.976. Recuperado de https://www. funcionpublica.gov.co/eva/gestornormativo/norma_ pdf.php?i=17168

República de Colombia. Presidencia de la República. (30 de marzo de 1989). Por el cual se expide el Estatuto Tributario de los Impuestos Administrados por la Dirección General de Impuestos Nacionales. [Decreto 624]. DO: 38.756. Recuperado de https:// www.cancilleria.gov.co/sites/default/files/tramites_ servicios/pasaportes/archivos/decreto_624_1989. pdf

República de Colombia. Presidencia de la República. (9 de julio de 1986). Por el cual se reglamenta la contabilidad mercantil y se expiden las normas de contabilidad generalmente aceptadas. [Decreto 2160]. DO: 37.545. Recuperado de http://www.suinjuriscol.gov.co/viewDocument.asp?id=1760654 
República de Colombia. Presidencia de la República. (29 de diciembre de 1983). Por el cual se introducen modificaciones al régimen del impuesto sobre las ventas. [Decreto 3541]. DO: 36.452. Recuperado de http://www.suin-juriscol.gov.co/viewDocument. asp?id=1530324

República de Colombia. Presidencia de la República. (30 de diciembre de 1982). Por el cual se revisan algunas normas en materia de procedimiento tributario $y$ se dictan otras sobre control de evasión de impuestos. [Decreto 3803]. DO: 36.162. Recuperado de http://www.suin-juriscol.gov.co/viewDocument. asp?id=1878671

República de Colombia. Presidencia de la República. (17 de septiembre de 1974). Por el cual se declara el estado de emergencia económica. [Decreto 1970]. DO: 34.170. Recuperado de http://www.suin-juriscol.gov. co/viewDocument.asp?id=1817517

República de Colombia. Presidencia de la República. (30 de septiembre de 1974). Por el cual se reorganizan el impuesto sobre la renta y complementarios. [Decreto 2053]. DO: 34.203. Recuperado de http://www.suinjuriscol.gov.co/viewDocument.asp?id=1917899

República de Colombia. Presidencia de la República. (21 de octubre de 1974). Por el cual se modifican normas procedimentales en materia tributaria $y$ se dictan otras disposiciones. [Decreto 2247]. DO: 34.195. Recuperado de http://www.suin-juriscol.gov.co/ viewDocument.asp?id=1425123

República de Colombia. Presidencia de la República. (20 de diciembre de 1974). Por el cual se dictan normas procedimentales en materia tributaria. [Decreto 2821]. DO: 34.245. Recuperado de http://www.suin-juriscol. gov.co/viewDocument.asp?ruta=Decretos $/ 1836211$ 
República de Colombia. Presidencia de la República. (27 de diciembre de 1973). Impuesto al valor agregado Creación en sustitución del impuesto a las ventas. Nuevo régimen por ley 23.349. [Ley 20631]. BO: A99.

República de Colombia. Presidencia de la República. (27 de marzo de 1971). Por el cual se reajustan las pensiones $y$ otras prestaciones de los empleados públicos $y$ trabajadores del sector privado y se provee a su financiamiento en el sector público. [Decreto 435]. DO: 33.302. Recuperado de http://www.suin-juriscol. gov.co/viewDocument.asp?id=1096921

República de Colombia. Presidencia de la República. (24 de junio de 1966). Por el cual se dictan unas disposiciones relativas al Impuesto sobre las Ventas y se modifican y suspenden otras. [Decreto 1595]. DO: 31.972. Obtenido de http://www.suin-juriscol.gov.co/ viewDocument.asp?id=1315194

República de Colombia. Presidencia de la República. (25 de febrero de 1965). Por medio del cual se reglamenta el Decreto-ley número 3288 de 1963 sobre impuesto a las ventas. [Decreto 377]. DO: 31.605. Recuperado de http://www.suin-juriscol.gov.co/viewDocument. asp?id=1084941

República de Colombia. Presidencia de la República. (diciembre de 30 de 1963). Por el cual se establece el Impuesto sobre las Ventas. [Decreto 3288]. DO: 31.265. Recuperado de http://www.suin-juriscol. gov.co/viewDocument.asp?id=1819854

República de Colombia. Corte Constitucional. (27 de abril de 2016). Sentencia C-209. Exp. D-10885. [MP: Jorge Iván Palacio Palacio]. Recuperado de http://www. corteconstitucional.gov.co/relatoria/2016/c-209-16. htm 
República de Colombia. Corte Constitucional. (26 de abril de 2005). Sentencia C-426. Exp. D-5419. [MP: Marco Gerardo Monroy Cabra]. Recuperado de http://www. corteconstitucional.gov.co/relatoria/2005/C-426-05. htm

República de Colombia. Corte Constitucional. (9 de diciembre de 1999). Sentencia C-987. Exp. D-2438. [MP: Alejandro Martínez Caballero]. Recuperado de http://www. corteconstitucional.gov.co/relatoria/1999/C-987-99. htm

República de Colombia. Corte Constitucional. (31 de octubre de 1996). Sentencia C-583. Exp. D-1304. [MP: Vladimiro Naranjo Mesa]. Recuperado de http://www. corteconstitucional.gov.co/relatoria/1996/C-583-96. htm

Soler, R. (2012). El impuesto justo y el IVA. Revista de Doctrina, 28(13-14), 19-34. Recuperado de https://dialnet. unirioja.es/servlet/articulo?codigo $=4072654$

Villasmil, M. y Polo, F. (2018). Estudio comparado sobre la regulación del impuesto al valor agregado (IVA) en Colombia y España. Dictamen Libre, 23, 11-31. Recuperado de https://revistas.unilibre.edu.co/index. php/dictamenlibre/article/view/5142/4360 
Artículo de reflexión derivado del proyecto de Investigación: "El Impuesto al Valor Agregado IVA en Colombia y sus antecedentes en la Historia" del Trabajo de Grado enmarcado en la Línea de investigación: derecho, estado, sociedad y cultura Grupo de investigación "Poder público y ciudadanía" Categoría $\mathrm{C}$ de especialización en derecho tributario del centro de investigaciones jurídicas y socio jurídicas, perteneciente a la facultad de derecho y ciencias sociales perteneciente a la Universidad Libre - Seccional Barranquilla. E artículo es el resultado de la revisión de los referentes nacionales jurídicos que han de ser analizados, comparados y contrastados con las prácticas actuales.

Eder Bermejo es Abogado, Especialista en Derecho Tributario de la Universidad libre, seccional Barranquilla (Colombia).

Milagros Villasmil es Posdoctor en Gerencia Pública y Gobierno (2013), Doctora en Ciencias Gerenciales (2008), Magíster Scientiarum en Gerencia Tributaria (2005), Licenciada en Contaduría Pública (2001), Diplomada Experta en NIIF-NIC del Instituto Europeo de Postgrado (2014). Docente Titular de Jornada Laboral Completa, e Investigadora adscrita en la Facultad de Ciencias Económicas Administrativas y Contables de la Universidad Libre Seccional Barranquilla (Colombia). Investigadora de la Red Académica Internacional de "Estudios Organizacionales en América Latina, el Caribe e Iberoamérica" (REOALCeI). Par Evaluador Internacional por Colciencias, Categorizada en Nivel Sénior como Investigadora por Colciencias. Vinculada al Grupo de Investigación Tendencias Contables, Económicas y Administrativas TCEA, categorizado en B. 